\title{
Impact of law against domestic violence (DV) on the reproduc- tive health of abuse victims in India.
}

\author{
Vaishali Patil, Jeff Luck
}

Publisher's Note: MDPI stays neutral with regard to jurisdictional claims in published maps and institutional affiliations.

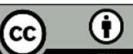

Copyright: @ 2021 by the authors. Submitted for possible open access publication under the terms and conditions of the Creative Commons Attribution (CC BY) license (http://creativecommons.org/licenses/by/4.0/).
1 Oregon State University, 1500 SW Jefferson Way, Corvallis, OR 97331

* Correspondence: patilva@oregonstate.edu; Jeff.Luck@oregonstate.edu

\begin{abstract}
Objectives: Assess the effect of law against DV on the prevalence of abuse and reproductive health. Methods: I analyzed DV data from National Family Health Surveys (NFHS 3\&4- 200506 and 2015-16) of India. The analytical sample was 69,438 NFHS3; n=66,013 NFHS4 of ever-married women aged 15-49 years. The main outcomes were unwanted pregnancy, termination of pregnancy, contraceptive use, age of first birth, and sexually transmitted infections in abuse victims and DV was the main independent variable. Covariates choice was guided by the socioecological model. I used the difference-in-difference model to compare the prevalence between the two surveys. Results: The prevalence of DV was 39.8\% in 2005-06 and 33.3\% in 2015-16. In 2005 38.5\% of victims were sterilized versus $1 \%$ having partner sterilized. In $201541 \%$ of victims were sterilized and only $0.29 \%$ had partners sterilized. There was no difference in the prevalence of victims experiencing STI between NFHS3 (16.5\%) and NFHS4 (16.2\%). About 29\% did not want a pregnancy in 2005 versus $16.5 \%$ in $2015 ; 12.7 \%$ had terminated pregnancy in 2005 versus $13.7 \%$ in $2015 ; 66.4 \%$ had first birth before 20 years in 2005 versus 49\% in 2015. The difference in female sterilization, male sterilization, unwanted pregnancy, and termination of pregnancy between two surveys was not significant. The probability of adolescent pregnancy increased by $3.8 \%$ points $(\mathrm{p}<0.001)$ and STIs decreased by $1 \%$ points $(p<0.01)$ in 2015. Conclusion: There was a mixed effect on reproductive health outcomes related to DV post-law. There is a need for stringent measures against DV to improve the sexual and reproductive health of women in India.
\end{abstract}

Keywords: Domestic violence; reproductive health; laws against domestic violence

\section{Introduction}

Gender inequity, discrimination, domestic violence, lack of autonomy are some common but rampant issues in many parts of the world, more so in Asian countries., ${ }^{1,2}$ Women face discrimination, in workplaces; they lack control in nearly all aspects of their life whether it is their upbringing, their marriage, their finances, sexual and reproductive health and so on. ${ }^{1}$ They are considered secondary citizens who need to be controlled and driven throughout their lives by men whether as father/s, brother/s, husband/s or son/s. The deeply embedded misogynistic attitudes have contributed immensely to a widespread culture of violence against women.3,4

The foundations of domestic violence against women go deep in the evolutionary history of humans where every attempt was made to establish tyranny over women. ${ }^{5}$ Though domestic violence is not restricted to a single gender, women tend to have a greater probability of receiving it due to traditional patriarchal system, emotional and economic dependence and inherent biological weakness. ${ }^{5}$ Women across the world gained a foothold for their cause with the 'Declaration on the Elimination of Violence Against Women' adopted by the United Nations General Assembly on December 20, 1993. ${ }^{6}$ The 1994 International Conference on Population and Development went a step further and drew links between violence against women and their reproductive health 
and rights. As per the UN definition of reproductive health it implies that people should be able to have a satisfying and safe sex life, have a capability to reproduce and have a freedom to decide if, when and how often to do so. ${ }^{7}$ There are various barriers to achieving this important among them being the prevalence of high-risk sexual behavior; discriminatory social practices; negative attitudes towards women and girls; and the limited power many women and girls have over their sexual and reproductive lives. One of the principles adopted as a guideline was that elimination of all kinds of violence against women and ensure women's control over their fertility. ${ }^{7}$

Though marital relationships are universally considered within a framework of interdependency and expectations its nature is quite different in India compared to that in the west. Dependency as a trait is seen in the social system and superior-subordinate roles are evident in all phases of life. This is very evident in marital rwlationships. ${ }^{8}$ In India females face a double onslaught- a persistent desire for the male child has reduced the girl child numbers and skewed the sex ratios and females who survive undergo discrimination at all fronts while growing up. ${ }^{9}$ Along with issues of gender equality there are numerous reproductive parameters that need attention in India- The maternal mortality rate is 190 deaths per 100,000; the fertility rate has decreased from 3.9 to 2.5; the contraceptive prevalence rate has moved up from $40.7 \%$ to $54.8 \%$; about $28 \%$ of children are born within 24 months of the previous birth; the median age of first marriage is 17.2 years and median age at first birth is 20 years; only about $37 \%$ of mothers had sought postnatal care within first two days delivery; and the women's share of HIV infections is about 39\%. India ranks 132 out of 148 countries in the Gender Inequality Index. ${ }^{10}$ Studies found that about $27 \%$ of women in India were married before the legal age of 18 (2018), nearly 21\% pregnancies were unwanted or mistimed and about $50 \%$ of maternal deaths among girls aged 15-19 years were due to unsafe abortion (2008). The contraceptive prevalence rate was $54.4 \%$ in 2019. Only about $21 \%$ of pregnant women utilized the full range of antenatal care (2013) and about $65 \%$ of mothers had sought postnatal care within first two days of delivery (2016). ${ }^{11}$

In India the 'Protection of Women Against Domestic Violence Act (PWDVA)' (2005) was passed in October 2006, after numerous attempts at stalling its passage. But even after a decade of its coming into effect critics have questioned its efficacy. ${ }^{12}$ PWDVA is considered a comprehensive law as it is holistic as it goes beyond the simple 'punishment' of the offender to provision of positive entitlements in form of monetary relief and protection of violence at home. ${ }^{12}$ Between two recent waves of survey India passed the law for protection of women against domestic violence but there is no study that has analyzed the efficacy of this law in affecting the prevalence of DV as well as any change in reproductive health outcomes linked to DV. This study is first of its kind to employ novel quasi-experimental method to measure change in DV and reproductive health using proxies for post law in India.

\section{Methods}

This study uses the socio-ecological model (SEM) to explain the pathway between DV and health outcomes in the abused. This study uses two waves of DHS national survey datasets from India that are responsible for collecting and disseminating nationally representative data on health and population from the developing countries. The NFHS3 collected detailed information from a sample selected from 29 states of India, from a sample of 109,041 households, 124,385 women age 15-49, and 74,369-men age 15-54. The NFHS 4 collected information from 29 states and all six union territories. A total of 601,509 households with 699,686 women and 112,122 men were successfully interviewed. Both NFHS 3 and NFHS 4 had a separate module of domestic violence included in the women's questionnaire. The sample sizes for each dataset are as below:

\begin{tabular}{cccc}
\hline Survey year & DV module sample & Analytical sample & Year Law was passed \\
\hline India (2005-06) & 83,703 & 69,438 & $2006(\mathrm{~J} \& \mathrm{~K} 2010)$ \\
\hline India (2015-16) & 79,729 & 66,013 & Same as above \\
\hline
\end{tabular}


Variables of interest:

a) Reproductive health outcomes-

1. Adolescent pregnancy: Pregnancy before age 20

2. Unintended pregnancy: Whether current pregnancy wanted

3. Termination of pregnancy: Whether women terminated pregnancy in preceding 12 months

4. Sexually transmitted infections: STI or STI-like symptoms in preceding 12 months of survey

5. Contraceptive use: Options of contraceptives used recoded to five categories- none, female sterilization, male sterilization, traditional methods and other modern methods.

6. Prenatal care: whether received any prenatal care for current pregnancy

7. Antenatal visits: Number of antenatal visits for current pregnancy recoded to two categories of less $(<=4)$ and appropriate $(>5)$.

b) Individual level covariates:

Age, religion, caste, region of country residing in, whether urban or rural, education level, wealth index, working status, relation to household, sex of household, whether respondent has own money/property, whether her father beat her mother, whether respondent justifies wife-beating, how much control the husband has on his wife, and whether the partner consumes alcohol.

\section{Results and Discussion}

Table 1. Prevalence of domestic violence in India.

\begin{tabular}{cccc}
\hline & \multicolumn{2}{c}{ India NFHS 3- 2005-2006 $(\mathbf{n = 6 9 , 4 3 8 )}$} \\
DV combined & Emotional DV & Physical DV & Sexual DV \\
$\mathrm{N}(\mathrm{W} \%)$ & $\mathrm{N}(\mathrm{W} \%)$ & $\mathrm{N}(\mathrm{W} \%)$ & $\mathrm{N}(\mathrm{W} \%)$ \\
$24,454(39.75)$ & $9,814(15.81)$ & $21,539(35.08)$ & $5,778(9.97)$ \\
\hline & India NFHS 4- 2015-2016 (n=66,013) \\
DV combined & Emotional DV & Physical DV & Sexual DV \\
\hline $\mathrm{N}(\mathrm{W} \%)$ & $\mathrm{N}(\mathrm{W} \%)$ & $\mathrm{N}(\mathrm{W} \%)$ & $\mathrm{N}(\mathrm{W} \%)$ \\
$20,968(33.32)$ & $8,372(13.84)$ & $18,680(29.78)$ & $4,372(6.96)$ \\
\hline
\end{tabular}

Table 2. Prevalence of the reproductive health outcomes in the abused married women.

\begin{tabular}{ccc}
\hline & NFHS3 (2005-06) & NFHS4 (2015-16) \\
\hline Current contraception & Any DV (N(W\%)) & Any DV (N(W \%)) \\
Not using & $10,522(45.84)$ & $9,696(44.12)$ \\
Female sterilization & $9,230(38.48)$ & $7,669(41.01)$ \\
Male sterilization & $245(1.01)$ & $78(0.29)$ \\
Other modern methods & $2,572(7.75)$ & $2,253(9.45)$ \\
Traditional methods & $1,885(6.92)$ & $1,272(5.15)$ \\
Suffered from any STIs & $3,707(16.55)$ & $3,663(16.14)$ \\
Adolescent pregnancy & $13,805(66.23)$ & $8,861(49.11)$ \\
Prenatal care (none) & $2,663(30.70)$ & $1,578(19.74)$ \\
Antenatal visits & & \\
None & $2,663(30.88)$ & $1,579(19.86)$ \\
Less & $6,732(62.20)$ & $3,842(45.07)$ \\
Appropriate & $1,052(6.92)$ & $2,538(35.08)$ \\
Unwanted pregnancy & $432(28.67)$ & $180(16.46)$ \\
Terminated pregnancy & $776(12.72)$ & $703(13.74)$ \\
\hline
\end{tabular}


Table 3. Reproductive health outcomes of ever-married women in India.

\begin{tabular}{ccc}
\hline Outcomes & NFHS3 (OLS) & NFHS4 (OLS) \\
\hline Contraception & Percentage point change (SE\%) \\
No method used & Reference & \\
Female sterilization & $1.9^{* * *}(0.4)$ & $1.5^{* * *}(0.4)$ \\
Male sterilization & $0.0(0.0)$ & $-0.1(0.0)$ \\
Other methods & $1.0^{* *}(0.0)$ & $0.0(0.0)$ \\
Any STIs & $5.8^{* * *}(0.0)$ & $5.8^{* * *}(0.0)$ \\
Adult pregnancy & $-2.5^{* * *}(0.0)$ & $-1.8^{* * *}(0.0)$ \\
Prenatal care (none) & $2.9^{* * *}(0.0)$ & $-0.0(0.0)$ \\
Antenatal visits & & \\
Appropriate & Reference & $-0.0(0.4)$ \\
None & $23.2^{* * *}(0.3)$ & $2.8^{* * *}(0.7)$ \\
Less & $0.4^{* * *}(0.0)$ & $4.6^{* *}(0.0)$ \\
Unwanted pregnancy & $5.2^{* * *}(0.0)$ & $-2.6^{* *}(0.0)$ \\
Terminated pregnancy & $-2.2^{* *}(0.0)$ & \\
\hline
\end{tabular}

In 2005-06, 39.8\% of women experienced any type of domestic abuse with $15.8 \%$ experiencing emotional abuse, $35.1 \%$ physical abuse and $10.0 \%$ sexual abuse whereas the estimated prevalence during $2015-16$ was $33.3 \%$ for any type of DV with $13.8 \%$ experiencing emotional violence, $29.8 \%$ physical violence and $7.0 \%$ sexual abuse. In $200538.5 \%$ of victims were sterilized versus 1\% having partner sterilized. In $201541 \%$ of victims were sterilized and only $0.29 \%$ had partner sterilized. There was no difference in prevalence of victims experiencing STI between NFHS3 (16.5\%) and NFHS4 (16.2\%). About 29\% did not want pregnancy in 2005 versus $16.5 \%$ in 2015 and about $13 \%$ had terminated pregnancy in 2005 versus about $14 \%$ in 2015 . About $66 \%$ had first birth before 20 years in 2005 versus $49 \%$ in 2015 . The number of women receiving prenatal care improved so did the number of antenatal visits in 2016 compared to 2006.

Unlike many other public health calamities DV is a 'hidden crime'. The victims do not share their feelings of helplessness, isolation, fear, shame and guilt. And even though there are recorded numbers they do not reflect the actual figures- it is said that there are about 35 assaults before a victim calls for help. ${ }^{13}$ Women in abusive relationships face a greater risk of unplanned pregnancies and may consider pregnancy termination, mostly out of medical setups. DV increases the likelihood of unwanted pregnancy, pregnancy termination with a general decrease in pre-conception and post-conception desire for pregnancy. ${ }^{14}$ Women in abusive relationships have lesser autonomy on their sexual lives leading to repeated unplanned pregnancies, induced abortions which may lead infertility and or maternal mortality. Domestic violence has been linked to unwanted pregnancy through its restrictive effect on the woman's ability to use contraception. ${ }^{15,16}$

\section{Conclusion}

The reproductive health and rights of women in India is appalling. More than half suffer from anemia, may face risk of death during pregnancy, and the country has a high number of adolescent pregnancies. Most of the domestic violence, sexual violence, and marital rape cases in India are also never reported. There is an urgent need to detect, quantify, accumulate and disseminate information related to DV. Change is needed in both intervention and prevention. Empowering girls and women, promoting education and understanding among boys and men and stronger legal resources would go a long way to reduce gender inequality and address domestic violence issue. 


\section{References}

1. ICRW. ADDRESSING INTIMATE PARTNER VIOLENCE IN SOUTH ASIA [Internet]. https://www.icrw.org/wp-content/uploads/2017/07/Partner-Violence-in-South-ASIA-Report-Final-file-17-04-2017.pdf. 2017 [cited 2018 May 27]. Available from: https://www.icrw.org/wp-content/uploads/2017/07/Partner-Violence-in-South-ASIA-Report-Final-file-17-04-2017.pdf

2. Raj A, McDougal L, Reed E, Silverman JG. Associations of marital violence with different forms of contraception: Cross-sectional findings from South Asia. Int J Gynaecol Obstet. 2015 Aug;130(0 3):E56-61.

3. Rani M, Bonu S. Attitudes Toward Wife Beating A Cross-Country Study in Asia. JIV. 2009 Aug;24(8):1371-97.

4. Heise LL, Kotsadam A. Cross-national and multilevel correlates of partner violence: an analysis of data from population-based surveys. The Lancet Global Health. 2015 Jun;3(6):e332-40.

5. Zukerman W. Domestic violence gets evolutionary explanation [Internet]. New Scientist. 2011 [cited 2018 Dec 8]. Available from: https://www.newscientist.com/article/dn20976-domestic-violence-gets-evolutionary-explanation/

6. García-Moreno C, World Health Organization. WHO multi-country study on women's health and domestic violence against women initial results on prevalence, health outcomes and women's responses. Geneva: World Health Organization; 2005.

7. UNPFA. Program of Action of the International Conference on Population Development [Internet]. 2014. Available from: https://www.unfpa.org/sites/default/files/pub-pdf/programme_of_action_Web\%20ENGLISH.pdf

8. Anand S, Sinha R, Singh L. Cognition related to domestic violence in India [Internet]. 2010 [cited 2018 Apr 5]. Available from: https://access.library.oregonstate.edu/pdf/1044173.pdf

9. Dasgupta S, Fletcher EK. Paying for Violence? Spousal Abuse and Son Preference in India. The Journal of Development Studies. 2018 Jul 3;54(7):1217-31.

10. El-Saharty S, Ohno N, Sarker I, Secci F, Rajan V. INDIA: MATERNAL AND REPRODUCTIVE HEALTH AT A GLANCE [Internet]. 2014 [cited 2018 Sep 19]. Available from: https://openknowledge.worldbank.org/bitstream/handle/10986/21291/936030BRI0Box30ledge0Note0KBIndia.2.pdf?sequence=1\&isAllowed =y

11. Pande R, Kurz K, Walia S, MacQuarrie K, Jain S. Improving the Reproductive Health of Married and Unmarried Youth in India. International Center for Research on Women. 2006;85.

12. Govindarajan P. A Curious Change to India's Domestic Violence Law [Internet]. The Diplomat. 2016 [cited 2018 Nov 3]. Available from: https://thediplomat.com/2016/11/a-curious-change-to-indias-domestic-violence-law/

13. Moss K. Shocking domestic abuse statistics don't show the real picture: it's even worse I Kate Moss. The Guardian [Internet]. 2016 Dec 14 [cited 2018 Dec 3]; Available from: https://www.theguardian.com/commentisfree/2016/dec/14/domestic-abuse-statistics-ons-worse-education

14. Begum S, Dwivedi SN, Pandey A, Mittal S. Association between domestic violence and unintended pregnancies in India: findings from the National Family Health Survey-2 data. The National medical journal of India. 2010;

15. Stephenson R, Koenig MA, Acharya R, Roy TK. Domestic Violence, Contraceptive Use, and Unwanted Pregnancy in Rural India. Stud Fam Plann. 2008 Sep;39(3):177-86.

16. Forrest $\mathrm{W}$, Arunachalam D, Navaneetham K. INTIMATE PARTNER VIOLENCE AND CONTRACEPTIVE USE IN INDIA: THE MODERATING INFLUENCE OF CONFLICTING FERTILITY PREFERENCES AND CONTRACEPTIVE INTENTIONS. Journal of Biosocial Science. 2018 Mar;50(2):212-26. 